\title{
ÁREAS VERDES PÚBLICAS EM JUIZ DE FORA, MG: UMA ANÁLISE DO \\ ESTADO DA ARTE ATUAL
}

\section{PUBLIC GREEN AREAS IN JUIZ DE FORA, MG: AN ANALYSIS OF THE CURRENT STATE OF THE ART}

\author{
Carlos Magno Adães Araujo \\ magnogeo@hotmail.com \\ Universidade Federal de Juiz de Fora \\ Cássia Castro Martins Ferreira \\ cassia.castro@ufjf.edu.br \\ Universidade Federal de Juiz de Fora
}

\begin{abstract}
RESUMO
Uma das características mais marcantes do espaço geográfico é sua transformação ininterrupta, fruto da relação dialética entre a sociedade e a natureza, na qual ambos se influenciam reciprocamente, transformando-se uns aos outros. Sob a égide do capitalismo, as transformações espaciais são rápidas e, muitas vezes, tão profundas que produzem impactos socioambientais e socioespaciais que são difíceis de serem mitigados. $O$ processo de urbanização demonstra claramente a magnitude das transformações pelas quais o homem e a natureza passam. Em Juiz de Fora, Minas Gerais, o rápido crescimento do município e de sua área urbana legaram à população um restrito e irregular número de áreas verdes públicas, fundamentais na melhoria da qualidade ambiental urbana e de vida da população. A análise da dinâmica demográfica e do Índice de Áreas Verdes de parques, praças, canteiros e da UFJF, de cada uma das 81 Regiões Urbanas do município e suas áreas de influência, reforçadas pelo cálculo e análise da Densidade de Áreas Verdes e do Percentual de Áreas verdes, se apresentam como importantes procedimentos na compreensão do status atual dessas áreas, que irão subsidiar propostas de políticas públicas que visem proteger, ampliar e construir novas áreas verdes, bem como facilitar que a legislação existente seja colocada efetivamente em prática.
\end{abstract}

Palavras-Chave: áreas verdes públicas, índice de áreas verdes, área de influência das áreas verdes, densidade de áreas verdes, percentual de áreas verdes.

\section{ABSTRACT}

One of the most striking features of the geographical space is your uninterrupted processing, fruit of the dialectic relationship between society and nature, in which both influence each other into each other. Under the aegis of capitalism, spatial transformations are quick and often so deep that produce environmental impacts and socioespaciais that are difficult to be mitigated. The urbanization process demonstrates clearly the magnitude of the transformations in which man and nature pass. In Juiz de Fora, Minas Gerais, the rapid growth of the city and its urban area population bequeathed a modal and irregular number of public green areas, essential in improving the urban and environmental quality of life of the population. The analysis of demographic dynamics and content of green areas of parks, squares, flowerbeds and 
UFJF, of each of the 81 municipal urban regions and their areas of influence, reinforced by the calculation and analysis of the Density of green areas and the percentage of green areas, present themselves as important steps in understanding the current status of these areas, which will subsidize public policy proposals aimed at protecting, expand and build new green areas, as well as facilitate that existing legislation be put effectively into practice.

KEYWORDS: public green areas, green areas index, area of influence of the green areas, green area density, percentual of green areas

\section{Introdução}

O processo de produção e transformação do espaço geográfico é permanente, ininterrupto. A humanidade sempre interagiu com o meio, adaptando e transformando esse meio de acordo com as possibilidades técnicas de cada época.

A urbanização da humanidade, acelerada pelo êxodo rural produzido pela industrialização, a partir do século XIX, e que tornou a maior parte da população do planeta urbana no século XXI, foi acompanhada por uma demanda crescente de matéria e energia que sustentassem o processo. Essa demanda, fruto de um modelo de desenvolvimento assentado na produção e no consumo de mercadorias, contribuiu para a transformação rápida do espaço geográfico em escala planetária, embora desigual entre as regiões e os lugares. Assim, os ambientes naturais, passaram por modificações profundas em seus ciclos naturais, que implicaram, dentre outros impactos negativos, na redução das áreas cobertas por vegetação nativa, que levou ao aumento da fragmentação florestal e de outros habitats, e na redução da biodiversidade do planeta.

Em Juiz de Fora, Minas Gerais, município fundado na segunda metade do século XIX, o processo de ocupação e exploração econômica ocorreu com vistas à implantação de um modelo de desenvolvimento que na época e, provavelmente ainda hoje, era sinônimo de dominação da natureza, vista como obstáculo ao desenvolvimento e que, portanto, deveria ser substituída por atividades capitalistas consideradas produtivas, como a pecuária, a agricultura, a indústria e, enfim, a própria urbanização. O município surge em um contexto escravista no qual as atividades primárias com o uso de mão de obra intensiva eram as principais fontes de geração de riqueza, em um país situado na periferia do sistema capitalista, e que via no controle e dominação da natureza o caminho rumo ao desenvolvimento. As consequências da adoção dessa perspectiva foram nefastas para o meio ambiente, sem falar no sistema fundiário extremamente 
concentrador de terras, gerador de disparidades sociais gritantes, legado do período colonial e perpetuado na história do país.

A ideia de uma natureza externa à humanidade contribuiu para acirrar a crise socioambiental gerada pela exploração demasiada do planeta. Postulamos a consideração do homem como parte da natureza, em um processo dialético de múltiplas influências, no qual evoluímos em conjunto.

Nesse contexto de rápidas e profundas transformações socioespaciais e socioambientais, surge um arcabouço legal que visa ordenar o uso e a ocupação do solo no meio urbano, e conciliar a expansão das atividades econômicas nas cidades à premissa da qualidade ambiental e de vida, ligadas, dentre outros fatores, à existência de cobertura vegetal urbana. Assim, as áreas verdes de suo público, relacionadas a uma série de benefícios para a dinâmica de funcionamento das cidades e da melhora da qualidade de vida da população urbana, se tornam imprescindíveis como uma das peçaschave para que as cidades e seus habitantes tenham acesso a serviços ambientais importantes, como a redução dos efeitos da poluição atmosférica e da temperatura, infiltração das águas pluviais, uso público com fins de lazer etc.

Assim, o objeto desta pesquisa é a análise, a quantificação e a espacialização das áreas verdes de uso público para a cidade de Juiz de Fora.

As classificações da cobertura vegetal no meio urbano variam de acordo com a finalidade ou função de cada espaço nas cidades, existindo diferentes definições baseadas tanto na legislação quanto na metodologia utilizada na definição de cada uma delas. Conforme Henke-Oliveira (1996, p. 14) "os conceitos empregados por pesquisadores, instituições e prefeituras envolvidas com programas de arborização urbana, nem sempre levam a um consenso geral".

Guzzo (2002) alerta sobre a dificuldade em relação aos termos utilizados para definir as áreas verdes urbanas, em especial sobre as distinções de expressões como áreas livres, espaços abertos, áreas verdes, sistemas de lazer, praças, parques urbanos, unidades de conservação em área urbana, arborização urbana.

A dificuldade em se utilizar uma terminologia padronizada revela a secundarização da cobertura vegetal na produção do espaço urbano, cujos impactos vão além da perda de qualidade de vida, envolvendo processos ecológicos e perda de biodiversidade. Como ressalta Willians (1995), diferentes discursos políticos para 
diferentes públicos, todos tendo como pano de fundo o bem público, em muitos casos advogam a favor de causas particulares. Além disso, a imitação ou reprodução de políticas específicas em contextos diferentes dos originais aumenta o risco de que as mesmas sejam mal sucedidas (MASSEY, 2009).

Com o objetivo de elucidar alguns conceitos desses espaços (cobertura vegetal) na cidade e de clarificar o que entendemos por áreas verdes, que representa nossa categoria de análise, iremos expor a seguir algumas das conceituações mais comumente adotadas no Brasil na definição das diferentes categorias de vegetação no meio urbano. Conforme recorda Rezende (2010), cada categoria tem sua importância a desempenhar na cidade, sendo subsistemas de um sistema de espaços livres. Os espaços livres, por sua vez, integram os demais, contrapondo-se aos espaços construídos nas áreas urbanas, de modo que o conceito deve ser integrado ao uso do espaço, sua escala e função, devendo, esta última, satisfazer três objetivos principais: ecológicos, estético e de lazer (LIMA et al, 1994).

Cavalheiro e Del Piccha (1992) argumentam que a expressão espaço livre deveria ser preferida em detrimento de áreas verde, uma vez que, para os autores, é uma expressão (ou conceito) mais abrangente, por incorporar, inclusive, as águas superficiais. A seguir, discorremos sobre os conceitos relacionados às áreas verdes.

Lima et al (1994) consideram o conceito de espaços livres bastante abrangente, porque integra os demais e se contrapõe ao espaço construído nas áreas urbanas. Os referidos autores exemplificam com as florestas amazônica e da Tijuca. A primeira não seria espaço livre, pois o elemento urbano não domina a paisagem. Já a segunda pode ser considerado como espaço livre, uma vez que está encravada na segunda maior metrópole brasileira.

Cavalheiro; Del Picha (1992), ao abordarem o conceito de área verde, consideram as mesmas sempre como espaços livres, inclusive preferindo este conceito ao de área verde, "por ser mais abrangente, incluindo, inclusive, as águas superficiais" (CAVALHEIRO; DEL PICHA, 1992, p. 30).

Os espaços abertos desempenham papel ecológico em sentido amplo, integrando espaços diferentes, com base nos enfoques estético, ecológico e de oferta de áreas para o lazer ao ar livre (CAVALHEIRO; DEL PICHA, 1992). Os espaços abertos, na leitura de Cavalheiro; Del Picha (1992), seriam um anglicanismo, fruto de um erro de tradução 
de free space (espaço livre) ao invés de open space (espaço aberto), carecendo, portanto, de fundamento quanto ao uso.

Nucci (1998, p. 215) fala de sistemas de espaços livres, assim definido por ele: "conjunto de espaços urbanos ao ar livre, destinados a todo tipo de utilização relacionada a pedestres (em oposição ao uso motorizado), descanso, passeio, prática de esporte, em geral, recreio e entretenimento em horas de ócio". O autor sugere $5 \mathrm{~m}^{2} / \mathrm{hab}$. de espaço livre público. Em todas as definições, parece lugar comum o entendimento de que o espaço (livre ou aberto) faz parte da paisagem, seja ela natural ou antropizada (LIMA et al, 1994).

Caporusso; Matias (2008, p. 72) salientam que "embora não haja uma definição consensual, o termo mais utilizado para designar a vegetação urbana é 'áreas verdes"”. De acordo com Cavalheiro et al (1999, p. 7) as áreas verdes são definidas como

um tipo especial de espaços livres cujo principal elemento é a presença de vegetação. Devem satisfazer as funções estética, ecológico-ambiental e lazer. A existência de vegetação e solo permeável devem ocupar pelo menos $70 \%$ da área, devendo propiciar condições para recreação.

Para Henke-Oliveira (1996, p. 17) o conceito de áreas verdes públicas

reconhece que estas são áreas permeáveis (sinônimo de áreas livres) públicas ou não, com cobertura vegetal predominantemente arbórea ou arbustiva (excluindo-se as árvores nos leitos das vias públicas) que apresentam funções potenciais capazes de propiciar um microclima distinto no meio urbano em relação à luminosidade, temperatura e outros parâmetros associados ao bem estar humano (funções de lazer); com significado ecológico em termos de estabilidade geomorfológica e amenização da poluição e que suporte uma fauna urbana, principalmente aves, insetos e fauna do solo (funções ecológicas), representando também elementos esteticamente marcantes na paisagem (função estética), independentemente da acessibilidade de grupos humanos ou da não existência de estruturas culturais como edificações, trilhas, iluminação elétrica, arruamento ou equipamentos afins; as funções ecológicas, sociais e estéticas poderão redundar entre si ou em benefícios financeiros (funções econômicas). 
Essa definição nos parece bastante abrangente e vai de encontro com nossa proposta. Entretanto, outras definições são imperiosas para que possamos mostrar clareza metodológica e conduzir a teoria ao encontro da prática no momento em que formos aplicar o conceito à cidade de Juiz de Fora. Lima et al (1994, p. 544), observam que "convergências na definição de Áreas Verdes encontram-se na literatura como áreas com predomínio de vegetação". Em pesquisa realizada pelos mesmos autores sobre conceitos como áreas verdes, áreas livres, arborização urbana e outros, foi constatado que "o enfoque das prefeituras é mais pragmático que conceitual, não havendo uma nítida hierarquia nas conceituações por esses agentes públicos" e que "todas as respostas recebidas concordaram que Área Verde é área coberta por vegetação" (LIMA et al, 1994, p. 546).

Cavalheiro et al (1999) chama a atenção para a falta de método na definição da cobertura vegetal, que gera discrepâncias enormes quando são denominadas indiscriminadamente como áreas verdes. Desse modo, definições como "áreas verdes”, "verde urbano" ou "manchas de verde" resultam em distorções no Índice de Áreas Verdes que vão de 50 a $90 \mathrm{~m}^{2}$ até menos de $5 \mathrm{~m}^{2}$ nas cidades. No mesmo sentido Nucci (2008, p. 30) alerta que

a comparação de índices de áreas verdes e de cobertura vegetal entre cidades também é um equívoco, pois $o$ índice desacompanhado da definição do termo "área verde", da escala espacial e do método de coleta dos dados não estabelece parâmetros de comparação. Por exemplo, dizer que a cidade de Vitória (ES) tem $95,55 \mathrm{~m}^{2} / \mathrm{hab}$ de área verde é fato que causa grande espanto. Uma análise mais aprofundada nos mostra que $35,31 \mathrm{~m}^{2} /$ hab são Unidades de Conservação, $55,27 \mathrm{~m}^{2} /$ hab são áreas verdes particulares, $2,88 \mathrm{~m}^{2} /$ hab são arborização de rua, e sobram, portanto, apenas $2,09 \mathrm{~m}^{2} /$ hab de áreas verdes públicas que englobam praças, trevos/canteiros, alamedas e calçadões. Veja que se fossem retirados os trevos/canteiros e alamedas ficaríamos com um número bem menor para o que poderia ser considerado realmente área verde, pois estaria ligada a um uso direto da população.

Ainda para o autor, a falta de definição clara acerca da expressão "área verde" e seus correlatos pode levar a interpretações equivocadas e a um uso político incorreto. 
Essa definição é indispensável na medida em que é a partir dela que os tipos de uso e funções desses espaços serão delineados.

De acordo com as classificações expostas, inferimos que as áreas verdes, mesmo que não haja consenso sobre sua definição possuem basicamente as seguintes características: são áreas livres (permeáveis) e abertas, predominam espécies arbustivas e arbóreas (nativas ou exóticas), englobam espaços públicos, como canteiros, praças e jardins e tem diferentes funções, que vão do lazer ao amortecimento de impactos da urbanização, passando pela preservação de espécies.

Cavalheiro; Del Picha (1992) ao abordarem o conceito de área verde enfatizam não considerar a grande paisagem livre de construções (zona rural dos municípios) e as unidades de conservação (strictu sensu). Neste trabalho, as unidades de conservação, à exceção dos parques, não se localizam no interior das regiões urbanas, que constituem nossa área de estudo, abordada adiante.

Os parques urbanos tiveram inspiração nos jardins ingleses, abertos e incorporados à estrutura urbana (ZANIN, 2002). No Brasil e na América do Sul, os parques foram criados com base nesse modelo, que permitiu a interação das pessoas de um modo diferente daquele que ocorre com as praças (ZANIN, 2002). Em nosso trabalho, levaremos em conta a definição de parques da Prefeitura de Juiz de Fora (PJF). Estes parques são unidades de conservação definidos, segundo a PJF, como sendo “áreas públicas destinadas à proteção da flora, fauna e belezas naturais, onde é permitida a visitação pública e a utilização para fins recreativos, educacionais e científicos. Para conciliar estes usos seu zoneamento e normas de uso" (PJF, 1999).

As praças, como áreas verdes, tem como principal função o lazer. De acordo com Rosset (2005), as praças podem ser desconsideradas como áreas verdes quando forem desprovidas de vegetação e a superfície for impermeabilizada. Em caso de presença de vegetação, se caracterizaria como um jardim. Em nosso trabalho, consideraremos as praças das Regiões Urbanas de Juiz de Fora como áreas verdes, desde que providas de cobertura vegetal, sobretudo arbórea.

Após perscrutar a literatura sobre áreas verdes, a definição de canteiro praticamente não foi encontrada. Canteiros são considerados, neste trabalho, como uma faixa de terreno, entre duas pistas de ruas ou avenidas, na qual sobressaem espécies arbóreas ou coexistam espécies vegetais herbáceas, arbustivas e, sobretudo, arbóreas, 
uma vez que este quesito (vegetação arbórea) é fundamental para o cálculo do IAV, conforme preconizamos na metodologia adotada. Sua largura, conforme constatado em campo, foi estipulada em até 4 metros, valor que coincide com a proposta de Zanin (2002) que, assim, nos permitirá comparações dos resultados de sua área de influência.

\section{Materiais e Métodos}

Para delimitação do tamanho, forma e distribuição das áreas verdes de uso público nas regiões urbanas de Juiz de Fora, foi utilizado o SIG - Sistema de Informação Geográfica - Arc Gis 10.0. Essa tecnologia permite capturar, armazenar, checar, manipular, analisar e exibir dados. O mapeamento das áreas verdes públicas se deu através da imagem aerofotográfica das regiões urbanas de Juiz de Fora cedida pela Prefeitura de Juiz de Fora. Esta imagem possui uma escala de 1:2000, o que contribuiu para precisão do mapeamento.

Após a delimitação das áreas verdes (canteiros, parques, praças e a Universidade Federal de Juiz de Fora - UFJF) foram calculados os valores de áreas verdes de uso público em metros quadrados $\left(\mathrm{m}^{2}\right)$.

A área urbana do município é dividida em 81 regiões urbanas, definidas pela

Lei 6910/86 em seu Cap. III, Art. 5º divide a Área Urbana do Distrito-sede Unidades Territoriais (UTs), que por sua vez, foi subdividida pela Lei Municipal 4219/89 que criou 81 Regiões Urbanas (RUs) que constituem unidades pequenas e coesas quanto às suas características, subdividindo a porção mais contínua e densamente ocupada da cidade, não abrangendo, no entanto, todo o Perímetro Urbano. E ainda, essa divisão por RU foi adotada pelo IBGE como unidade espacial básica para censo demográfico, o que possibilita uma maior gama de comparações (COSTA; FERREIRA, 2007, p.11).

A definição das regiões urbanas como unidade de análise se justifica porque índices como o IAV são dependentes da população, sendo, portanto o meio para obtermos a população da cidade em unidades menores e não somente para toda a cidade. A localização das 81 regiões urbanas da cidade pode ser visualizada no mapa 1.

Para calcular o IAV, levando em consideração a Universidade Federal de Juiz de Fora - UFJF que podemos considerar como área verde e o Parque da Lajinha, 
observamos que estes não estão inseridos dentro de uma única Região Urbana. Para estas duas situações, foi tomado o critério de somar o total da população das Regiões Urbanas do entorno imediato a essas áreas e calcular o IAV a partir dessa soma populacional e não individual de cada Região Urbana.

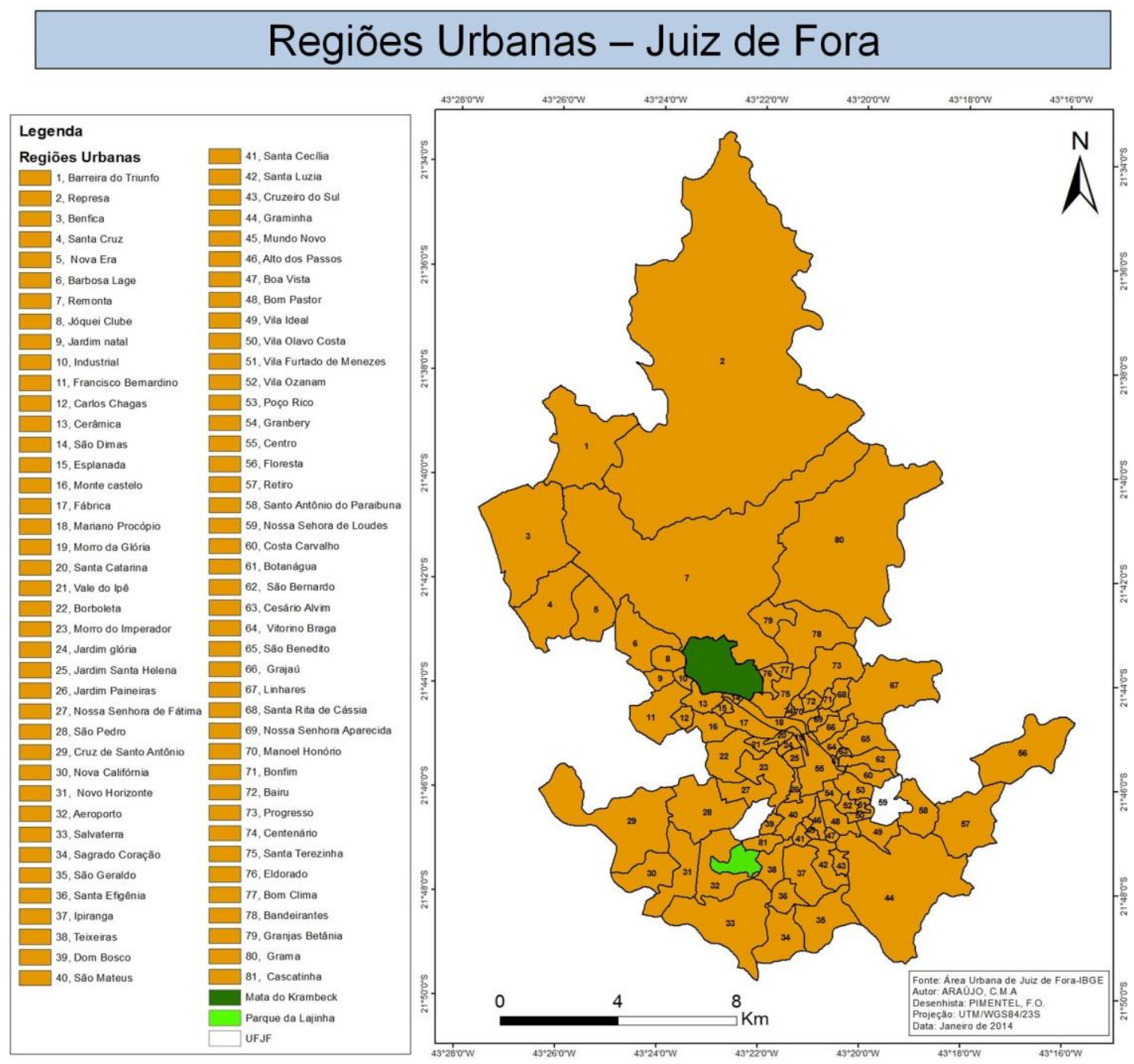

Mapa 1- Regiões urbanas da cidade de Juiz de Fora - MG

Foi feito o somatório de áreas verdes por regiões urbanas e tendo o número de habitantes obtidos do Censo de 2010 (IBGE, 2010), estes valores foram sendo inseridos na seguinte equação:

$$
\mathrm{IAV}=
$$

Geo UERJ. Rio de Janeiro - Ano 16, no ${ }^{\circ}$ 25, v.2, $2^{\circ}$ semestre de 2014, pp.250-275

ISSN: 1415-7543 E-ISSN: 1981-9021

http://www.e-publicacoes.uerj.br/index.php/geouerj 


\section{$\mathrm{N}^{\circ}$ habitantes das RUs}

Obtendo-se o índice de áreas verdes (IAV) para as 81 regiões urbanas de Juiz de Fora. Foi calculada também a densidade de áreas verdes (DAV), representada pela:

$$
\text { DAV }=\frac{\text { superfície da área verde }}{\text { superfície da área de influência }}
$$

E o percentual de áreas verdes (PAV), representado pelo somatório total das áreas verdes públicas por RU dividido pela área de cada RU, segundo a equação:

$$
\mathrm{PAV}=\sum \mathrm{AV} \div \mathrm{AT}
$$

Na sequência foi utilizada a ferramenta buffer localizada no Arctoobox, para delimitar a área de influência dos parques e UFJF (3000 metros), praças (800 metros) e canteiros (500 metros). Conforme metodologia utilizada por Henke Oliveira (1996), Zanin (2002) e aplicada por Rosset (2005), estas áreas de influência foram definidas, tomando como referência a estimativa da média da distância máxima que uma pessoa caminha para atingir a área verde, a partir da sua residência, sendo ainda delimitado em função do tamanho e característica da área verde.

No caso do Parque da Lajinha e da UFJF, que não estão inseridos em RUs específicas, mas são ladeados por muitas delas, calculamos suas áreas de influência sobre as RUs do entorno, de modo que algumas RUs ficam destituídas de áreas verdes quando consideramos somente o IAV, mas são parcial ou totalmente abrangidas pelas áreas de influência dessas duas áreas verdes. Os parques do Museu Mariano Procópio e Halfeld estão no interior das RUs Mariano Procópio e Centro, respectivamente, de modo que, nesse caso, calculamos tanto o IAV das RUs levando em consideração a inserção dessas duas áreas verdes, quanto às áreas de influência das mesmas.

\section{Resultados e Discussão}


A partir do uso de índices como o IAV, DAV, PAV e o cálculo das áreas de influências dos parques, praças, canteiros e da UFJF, esperamos aferir as condições em que se encontram essas áreas verdes públicas atualmente, tanto em relação ao IAV mínimo recomendado pela Sociedade Brasileira de Arborização Urbana - SBAU quanto em termos de condições de uso (manutenção, existência de equipamentos etc). A partir dos dados resultantes, esperamos contribuir com proposições que visem à manutenção, ampliação e, quiçá, a criação de outras áreas verdes públicas, em especial nas RUs destituídas da presença das mesmas. Para isso, ter ciência do número, da distribuição e do tamanho dessas áreas é fundamental para avançarmos no sentido da contemplação de toda a população de todas as RUs com as áreas verdes de uso público.

Como pode ser verificado no mapa 02 , nada menos que 48 dentre as 81 RUs do município apresentam IAV igual a zero, ou seja, não apresentam sequer o mínimo de $15 \mathrm{~m}^{2}$ de área verde por habitante preconizado pela SBAU. Somente 2 RUs apresentam IAV superior a $15 \mathrm{~m}^{2} / \mathrm{hab}$. São elas: RU 18 (Mariano Procópio) e RU 23 (Morro do Imperador). RUs densamente povoadas apresentam IAV de até $3 \mathrm{~m}^{2} / \mathrm{hab}$, bem abaixo do mínimo recomendado pela SBAU, na Carta de Londrina e Ibiporã.

Costa; Ferreira (2009), analisando 24 RUs da área central de Juiz de Fora encontraram apenas uma RU com IAV superior a $15 \mathrm{~m}^{2} / \mathrm{hab}$, a RU 18 . Essa RU é um parque urbano que abriga um dos mais importantes museus imperiais do país, tombado como patrimônio do município. É provável que o IAV elevado aferido nessa RU seja reflexo justamente do tombamento, haja vista ser uma RU valorizada em que a implacável especulação imobiliária talvez já tivesse feito suprimir a vegetação. Curiosamente, a RU 23 cujo IAV também está acima da média das demais e da média preconizada da SBAU, também é tombada pelo município como patrimônio ambiental. Seria lícito, portanto, concluirmos que onde não houve efetiva intervenção do poder público, a vegetação foi dizimada para atender a interesses privados?

Os dados que obtivemos convergem com os de Costa; Ferreira (2009), porém, como analisamos todas as 81 RUs, também destacamos a RU Morro do Imperador, que não entrou na pesquisa das autoras, com IAV de 478,81 $\mathrm{m}^{2} / \mathrm{hab}$. Essa RU está frontalmente voltada para a região central da cidade, sendo um dos marcos da paisagem urbana de Juiz de Fora. 
O IAV total das 81 RUs de Juiz de Fora é de 4,7m²/hab. Comparando nossos resultados com outras cidades, observamos que a situação de Juiz de Fora se aproxima daquela de muitas cidades brasileiras, como revelam os trabalhos de Henke-Oliveira (1996) para o município de São Carlos/ SP, Zanin (2002) e Rosset (2005) para Erechim/RS, Oliveira; Jesus (2011) para Rio Branco/ AC, Harder; Ribeiro; Tavares (2005) para Vinhedo/SP e Carvalho (2001) para Lavras/MG. Em todos esses casos o IAV fica invariavelmente abaixo dos $15 \mathrm{~m}^{2} / \mathrm{hab}$, recomendados pela SBAU, o que nos permite especular acerca da existência ou não de preocupações sérias quanto à importância e a necessidade das áreas verdes urbanas.

Um resultado interessante foi encontrado por Pirovani et al (2012), para Cachoeiro do Itapemirim/ES, no qual o IAV da cidade como um todo ficou em 35,4 $\mathrm{m}^{2} / \mathrm{hab}$., mas quando somente as praças foram analisadas, o IAV ficou em apenas $0,95 \mathrm{~m}^{2} /$ hab. Esses dados dão margem à interpretação que fazemos para Juiz de Fora e que, acreditamos, pode ser extrapolada para outras realidades, qual seja a de que a análise do IAV deve se relacionar com os potenciais benefícios que a cobertura vegetal pode proporcionar, ou seja, do ponto de vista dos espaços disponíveis para o uso coletivo, como as praças e parques, o IAV está aquém do mínimo ideal mas, quando a vegetação é analisada para a cidade, o IAV pode se mostrar maior, independente do uso ou não dos espaços vegetados pela população. Em Juiz de Fora, nos restringimos à análise das áreas verdes de uso público. Se áreas verdes privadas e as Reservas Biológicas, no qual é vetada a visitação pública, tivessem entrado no cálculo do IAV para toda a cidade, e não somente as áreas verdes de uso público para cada RU, certamente o resultado em termos de benefícios ecológicos para o município e a população apareceriam mais explicitamente, a despeito dessas áreas vegetadas serem ou não utilizadas com fins públicos.

No município de Juiz de Fora, Costa; Ferreira (2009, 2007), Ferreira (2008) e Rezende (2010), utilizaram o IAV para as RUs, com resultados que passaremos a comparar com os nossos. Esses trabalhos utilizaram dados de demografia referentes a 2000. De todos esses trabalhos, o nosso foi o mais ambicioso por procurar estudar as 81 RUs da cidade, além de utilizar a DAV e o PAV para enriquecerem a análise cujo foco é o IAV. Rezende (2010) estudou 19 RUs, com base nos dados de Costa; Ferreira (2009), que estudaram 24 RUs. Seus resultados são muito próximos do nosso, já que a 
metodologia foi basicamente a mesma. No entanto, os dados mais recentes de que dispomos revelam algumas mudanças. A título de exemplo dessas mudanças, podemos citar a RU 23 (Morro do Imperador) que, na pesquisa de Rezende (2010) apresentava o IAV de $1109 \mathrm{~m}^{2} / \mathrm{hab}$ e, atualmente, com base nos dados do recenseamento de 2010, realizado pelo IBGE, a mesma RU apresenta IAV de 478,81 $\mathrm{m}^{2} / \mathrm{hab}$., ou seja, caiu em dez anos para menos da metade! Esse fato é tributário, certamente, do crescimento demográfico na RU no período de dez anos e não da supressão da vegetação, uma vez que a área é tombada.

Tomando como base a Tabela 1, verificamos que houve em algumas regiões urbanas aumento ou decréscimo das áreas verdes de uso público, em função do incremento populacional ou mesmo diminuição, não verificamos um aumento real das áreas verdes de uso público, portanto, o que levou a alteração dos índices, nos dois períodos, foi à mudança na quantidade de população residente em cada região urbana. Foram comparadas apenas estas Regiões Urbanas, em função dos estudos realizados anteriormente só terem apresentado seus resultados para estas RUs.

Tabela 1- Índice de áreas verdes em 2000 e 2010.

\begin{tabular}{|c|l|c|c|}
\hline \multicolumn{2}{|c|}{ Região Urbana } & $2000\left(\mathrm{~m}^{2} / \mathrm{hab}\right)$ & $2010\left(\mathrm{~m}^{2} / \mathrm{hab}\right)$ \\
\hline 20 & Santa Catarina & 0,9 & 1,03 \\
\hline 23 & Morro do Imperador & 1109 & 478,81 \\
\hline 40 & São Mateus & 0,3 & 0,1 \\
\hline 53 & Poço Rico & 1,5 & 2,5 \\
\hline 55 & Centro & 1,4 & 1,8 \\
\hline 81 & Cascatinha & 105,5 & 109,6 \\
\hline
\end{tabular}

Fonte: COSTA e FERREIRA (2009), REZENDE (2010), ARAÚJO (2014).

Organizado por Araújo e Ferreira, 2014. 


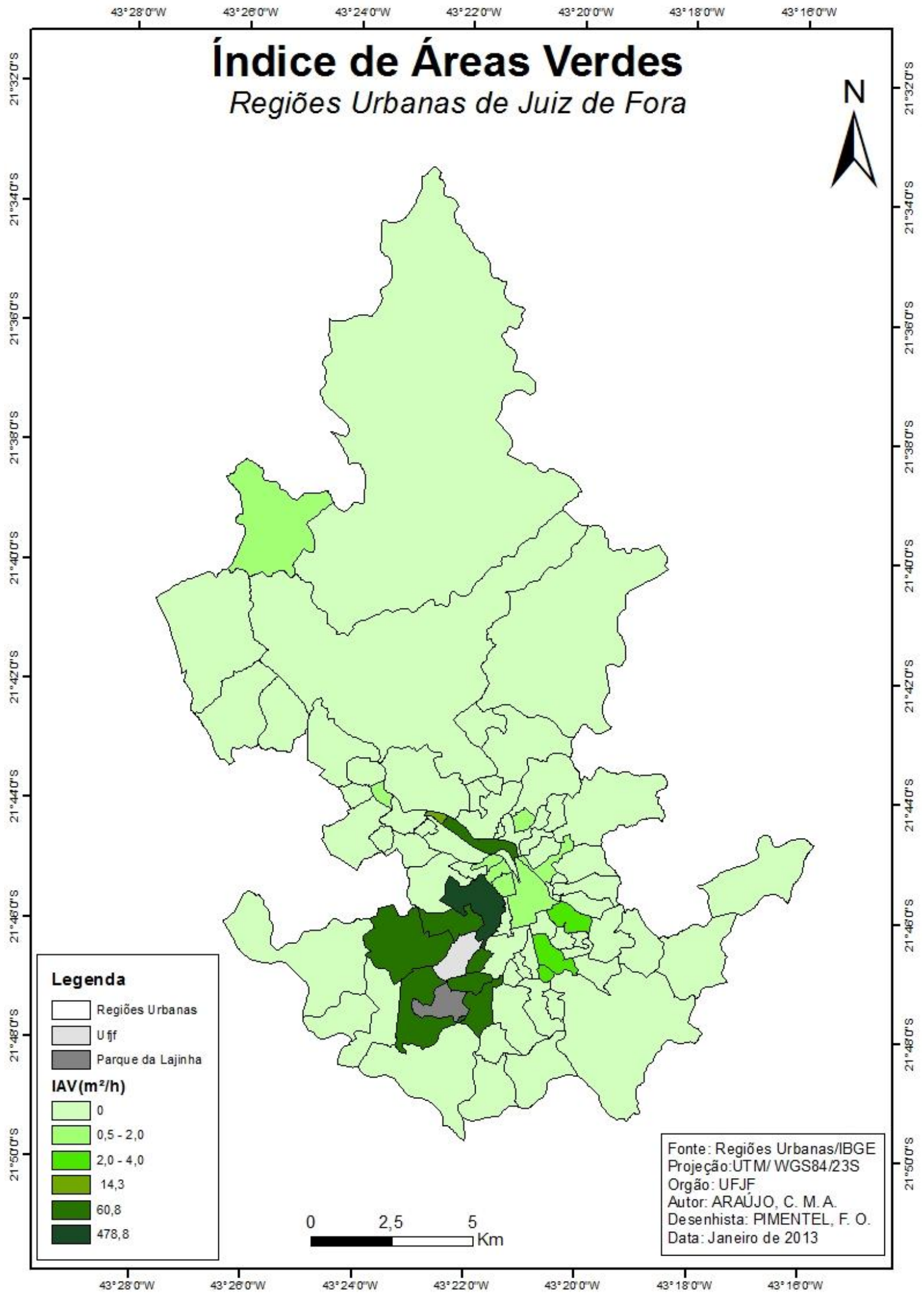

Geo UERJ. Rio de Janeiro - Ano 16, nº. 25, v.2, $2^{\circ}$ semestre de 2014, pp.250-275

ISSN: 1415-7543 E-ISSN: 1981-9021

http://www.e-publicacoes.uerj.br/index.php/geouerj 
Mapa 2 - Índice de áreas verdes por RU em Juiz de Fora

O cálculo da DAV e sua espacialização no mapa 3, comparado com a área de influência das áreas verdes públicas selecionadas em Juiz de Fora, demonstra que a melhor alternativa para aumentar o IAV das RUs do município é a criação de praças, pois nestas a DAV é maior, embora a área ocupada seja menor que a dos parques que, por sua vez, apresentam área de influência maior, conforme revela o mapa 3, mas apresentam menor DAV. Desse modo, para o morador de determinada RU, é mais fácil aproveitar os benefícios de uma praça em sua RU do que se deslocar até um parque em outra RU. Esse resultado se aproxima do encontrado por Rosset (2005) para Erechim (RS).

43 RUs apresentam DAV igual a zero. São elas:, Bom Clima, Borboleta, Carlos Chagas, Centenário, Cerâmica, Cesário Alvim, Costa Carvalho, Cruz de Santo Antônio, Cruzeiro do Sul, Esplanada, Floresta, Francisco Bernardino, Fábrica, Grajaú, Grama, Graminha, Granjas Betânia, Ipiranga, Jóquei Clube, Jardim Natal, Linhares, Manoel Honório, Monte Castelo, Nova Califórnia, Nova Era, Novo Horizonte, Remonta, Represa, Retiro, São Bernardo, São Geraldo, Sagrado Coração, Salvaterra, Santa Cecília, Santa Cruz, Santa Efigênia, Santa Rita de Cássia, Santo Antônio do Paraibuna, Vale do Ipê, Vila Furtado de Menezes, Vila Ideal, Vila Olavo Costa e Vila Ozanan. Conforme o mapa 3 informa, essas RUs estão dispersas pela área urbana de Juiz de Fora, dado que confirma que as áreas verdes de uso público são mal distribuídas e que, assim, a população é desigualmente contemplada pelas mesmas, implicando, por consequência, no benefício de uma parcela minoritária quando desconsideradas as áreas de influência.

DAV variando de 0,1 até $10 \mathrm{~m}^{2}$ de área verde/ $\mathrm{Km}^{2}$ abrange $27 \mathrm{RUs}$, que são: Alto dos Passos, Bairu, Bandeirantes, Barbosa Lage, Barreira, Benfica, Boa Vista, Bonfim, Eldorado, Graminha, Granbery, Industrial, Jardim Glória, Jardim Paineiras, Jardim Santa Helena, Morro da Glória, Mundo Novo, Nossa Senhora Aparecida, Nossa Senhora de Lourdes, Progresso, São Benedito, São Dimas, São Mateus, Santa Catarina, Santa Luzia, Santa Terezinha e Vitorino Braga. Finalmente, DAV acima de $10 \mathrm{~m}^{2} \mathrm{de}$ área verde/Km² é encontrada em 5 RUs: Bom Pastor, Centro, Mariano Procópio, Morro 
do Imperador e Poço Rico. A RU Morro do Imperador destoa das demais RUs por apresentar DAV superior a $897 \mathrm{~m}^{2}$ de área verde $/ \mathrm{Km}^{2}$, índice relacionado tanto à área da RU quanto à pequena população absoluta da mesma. Depois desta, as RUs Aeroporto e Cascatinha $\left(768,83 \mathrm{~m}^{2}\right.$ de área verde $/ \mathrm{Km}^{2}$, cada uma), Dom Bosco e Nossa Senhora de Fátima $\left(389,44 \mathrm{~m}^{2}\right.$ de área verde $/ \mathrm{Km}^{2}$, cada uma), São Pedro $\left(389,44 \mathrm{M}^{2}\right.$ de área verde $\left./ \mathrm{Km}^{2}\right)$ e Teixeiras $\left(379,38 \mathrm{~m}^{2}\right.$ de área verde $\left./ \mathrm{Km}^{2}\right)$, são as RUs com maior DAV. DAV entre 10 e $50 \mathrm{~m}^{2}$ de área verde/ $\mathrm{Km}^{2}$, é encontrada nas RUs Bom Pastor Centro, Mariano Procópio e Poço Rico.

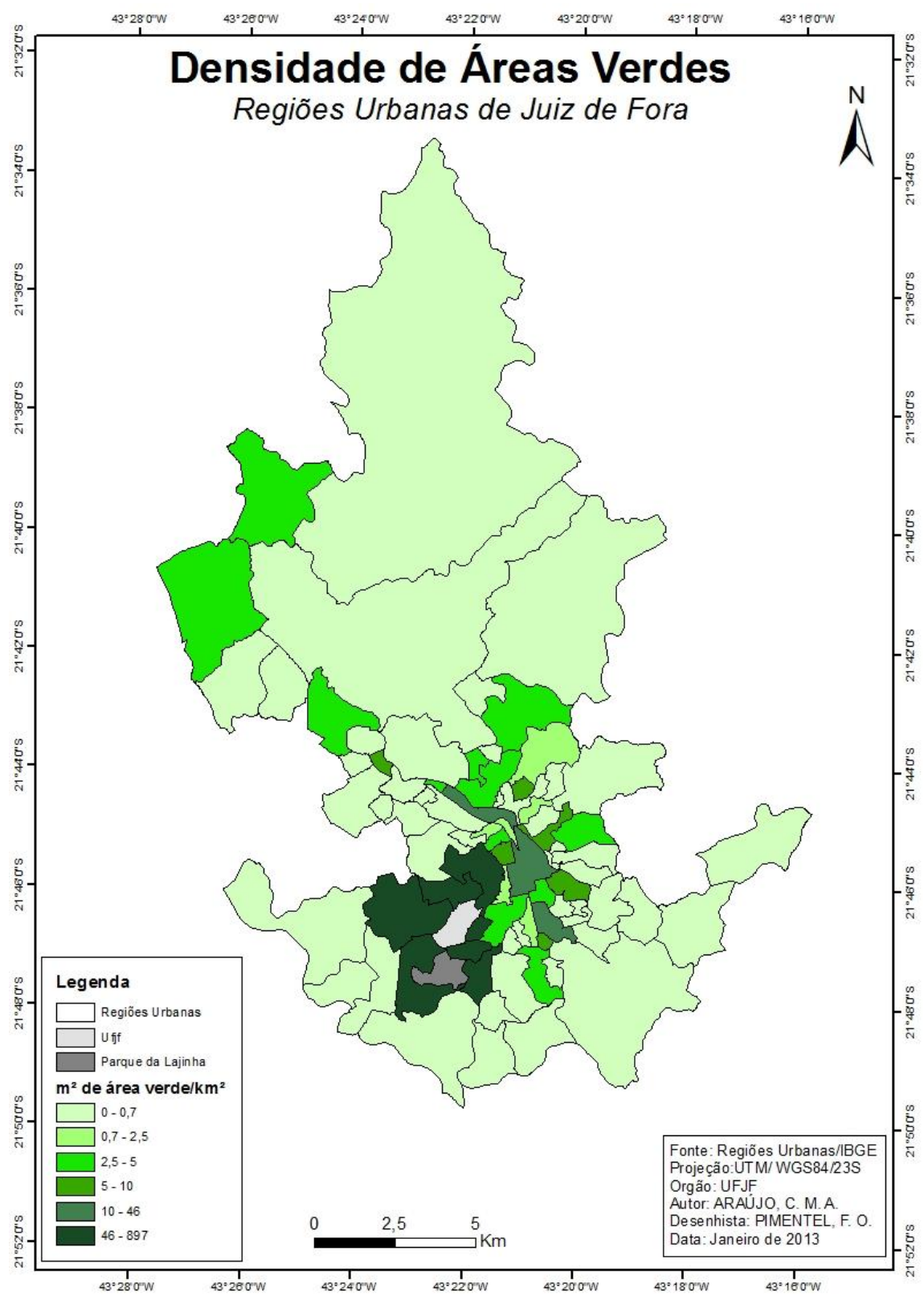

Geo UERJ. Rio de Janeiro - Ano 16, no. 25, v.2, $2^{\circ}$ semestre de 2014, pp.250-275 ISSN: 1415-7543 E-ISSN: 1981-9021

http://www.e-publicacoes.uerj.br/index.php/geouerj 
Mapa 3 - Densidade de área verde por RU em Juiz de Fora

Mais da metade das RUs (43 RUs) tem DAV igual à zero. O restante das RUs apresentam DAV variando entre 0 e $10 \mathrm{~m}^{2}$ de área verde $/ \mathrm{Km}^{2}$ (27 RUs) e 10,1 e $50 \mathrm{~m}^{2}$ de área verde $/ \mathrm{Km}^{2}$, ou seja, assim como no caso do IAV, a DAV também é baixa nas RUs de Juiz de Fora. Estratégias simples como o plantio de mudas nos espaços livres existentes aumentaria a DAV, colaborando para a melhoria da qualidade ambiental nas RUs.

As áreas de influência dos parques é que mais transcende os limites das RUs onde eles estão inseridos, seguido pelas praças e canteiros. Esse resultado era esperado, uma vez que o raio adotado como área de influência de parques, praças e canteiros foi de 3.000, 800 e 500 metros, respectivamente. Henke-Oliveira (1996) e Rosset (2005), também observaram que as áreas de influência das áreas verdes com as quais trabalharam em São Carlos, SP e Erechim, RS, ultrapassava, em muitos casos, os limites da localização de cada uma delas, seja em um bairro, seja em um setor. Nas RUs de Juiz de Fora não é diferente, sobretudo no que se refere aos parques.

As diretrizes do PDDU (2004) com relação ao patrimônio ambiental de Juiz de Fora não se materializaram, ficando patente que o IAV das RUs fica longe de atender satisfatoriamente a população, em especial se considerarmos as áreas de influência dos parques, apresentadas no mapa 4, que deixam RUs inteiras desprovidas. Como o raio de influência dos parques é maior e estes também possuem área maior que praças e canteiros, fica explícito que as RUs de Juiz de Fora não são adequadamente atendidas por esse equipamento urbano. Além disso, conforme também destacado por Rezende (2010), a manutenção dos parques se encontra em situação precária, apesar de contarem com equipamentos de lazer e desportes. Em campo, foi possível observar falta de poda à grama, bancos quebrados e pichados e brinquedos infantis enferrujados e quebrados. A questão da segurança também preocupa, pois nas incursões a campo, em várias áreas verdes não foi observado a presença de nenhum tipo de segurança, seja da PJF, seja a presença ostensiva da Polícia Militar.

55 RUs são totalmente influenciadas pelos Parque Halfeld (RU Centro), Parque do Museu Mariano Procópio (RU Mariano Procópio) e Parque da Lajinha (não está localizado em nenhuma RU, conforme demonstra o mapa 1), totalizando 
aproximadamente 2/3 das 81 RUs de Juiz de Fora. Esse dado permite considerar que se a cidade possuísse mais parques e se eles fossem melhor distribuídos, a carência de áreas verdes públicas, como as praças, poderia ser atenuada pela presença dos parques, em função de suas áreas de influência. Quanto às RUs parcialmente influenciadas pelos parques e RUs não influenciadas pelos parques, existe equilíbrio, pois, nos dois casos são 13 RUs. De qualquer forma, 13 RUs não são influenciadas por parques, mesmo que, eventualmente, possam ser influenciadas por outras áreas verdes públicas menores.

Com relação às praças, ocorre uma distribuição mais equilibrada de suas áreas de influência, conforme revela o mapa 4. Das 81 RUs, 14 não são influenciadas pelas praças, considerando um raio de 500 metros. A área de influência das praças é reveladora de um dado notável, pois considerando que 49 RUs não possuem sequer uma área verde pública, outras 35 pelo menos podem ser facilmente acessadas pela população a pé, se considerarmos aqui a conceituação, já abordada, das áreas de influência oferecida por Henke-Oliveira (1996). É interessante chamar a atenção para o fato de que, no cálculo das áreas de influência das praças, não levamos em consideração a área total das praças. Como a área entre elas varia, deduz-se que praças maiores tem maior capacidade de atender à população do entorno, ao passo que praças menores apresentam maior dificuldade nesse sentido.

Por predominarem na região central da cidade, as praças apresentam uma sobreposição em suas áreas de influência também nessa região, o que abre caminho a algumas considerações. A região central foi claramente priorizada em relação às regiões periféricas no que tange à instalação desse equipamento urbano. Embora existam praças em quase todas as RUs, muitas não entraram em nossa classificação por serem impermeabilizadas. Assim, se nos atentarmos para as diretrizes do PDDU no que concerne à arborização da cidade em seu item VII "implantar ou ativar a arborização urbana", e as finalidades, objetivos e competências do COMDEMA, no item XIX do artigo $6^{\circ}$, "propor normas para elaboração e elaborar, de forma integrada e articulada, planos, programas e projetos de arborização urbana, unidades de conservação e planos de manejo dessas unidades", concluímos que, à exceção da região central da cidade, cuja ocupação é mais antiga e, portanto, a existência da maioria das praças que consideramos áreas verdes públicas também são antigas, o arcabouço jurídico criado na esteira de uma tendência observada em todo o país nas décadas de 1980 e 1990, não foi 
suficiente para materializar as ações necessárias para fomentar a criação, ampliação e manutenção das praças e outras áreas verdes públicas nas RUs do município, fato que denota a secundarização da questão ambiental urbana no que tange a essas áreas e seus atributos benéficos para a dinâmica de formação de espaços de uso público mais salubres que as praças cimentadas que predominam nas RUs afastadas da região central da cidade.

Enquanto a área total e a área de influência dos parques é maior e, portanto, para as RUs tem a capacidade aumentar e equilibrar o IAV total, no interior de cada RU a melhor estratégia seria a construção de praças, que aumentam o IAV na RU. Como a área de influência não considera a população, para aumentar o IAV, a construção de praças seria uma alternativa viável, pois o cálculo deste depende da população, cuja densidade mostra a necessidade de aumentar as áreas verdes. Isso é válido inclusive para as RUs cujo cálculo do IAV foi feito considerando-se o Parque da Lajinha e a UFJF, pois, embora apresentem IAV acima da recomendação da SBAU e da média das demais RUs, é preciso levar em conta a situação no interior dessas RUs. Durante a pesquisa, realizamos um exercício e constatamos que, se o Parque da Lajinha e a UFJF não tivessem entrado no cálculo, o IAV dessas RUs seria igual a zero ${ }^{1}$. Nas RUs destituídas de áreas verdes públicas, o IAV é igual a zero, independentemente da população relativa.

Os canteiros tem, dentre as áreas verdes de uso público consideradas, tanto as áreas de influência mais circunscritas quanto são encontrados em apenas 11 RUs. São elas, conforme revela o mapa 4: São Mateus, Santa Luzia, Cruzeiro do Sul, Graminha, Mundo Novo, Alto dos Passos, Boa Vista, Bom Pastor, Poço Rico, Granbery e Centro. Canteiros em outras RUs não se enquadraram em nossa classificação por serem impermeabilizados e sem a presença de vegetação de porte arbóreo. Assim como nos casos dos parques e praças, canteiros considerados áreas verdes de uso público estão limitados à região central da cidade, sobretudo em duas importantes avenidas que cortam a cidade em sua porção central: a Avenida Barão do Rio Branco (que contava até recentemente com uma área maior de canteiros que, por terem sofrido uma intervenção no sentido da colocação de placas de alvenaria em suas bordas, não

\footnotetext{
${ }^{1}$ São elas: Aeroporto, Cascatinha, Dom Bosco, Nossa Senhora de Fátima e Teixeiras. A RU São Mateus teria IAV igual a $0,04 \mathrm{~m}^{2} / \mathrm{hab}$.
}

Geo UERJ. Rio de Janeiro - Ano 16, nº. 25, v.2, $2^{\circ}$ semestre de 2014, pp.250-275

ISSN: 1415-7543 E-ISSN: 1981-9021

http://www.e-publicacoes.uerj.br/index.php/geouerj 
entraram em nossa classificação, apesar de serem arborizados) e a Avenida Presidente Itamar Franco (antiga Avenida Independência). Mais uma vez, a despeito do aumento da frota de veículos automotores e, consequentemente, da abertura de novas vias que acompanham o crescimento da cidade, o PDDU não teve levado em conta sua premissa de que, no processo de produção do espaço urbano, a vegetação fosse considerada como um dos atributos a serem priorizados na melhoria das condições ambientais desse mesmo espaço.

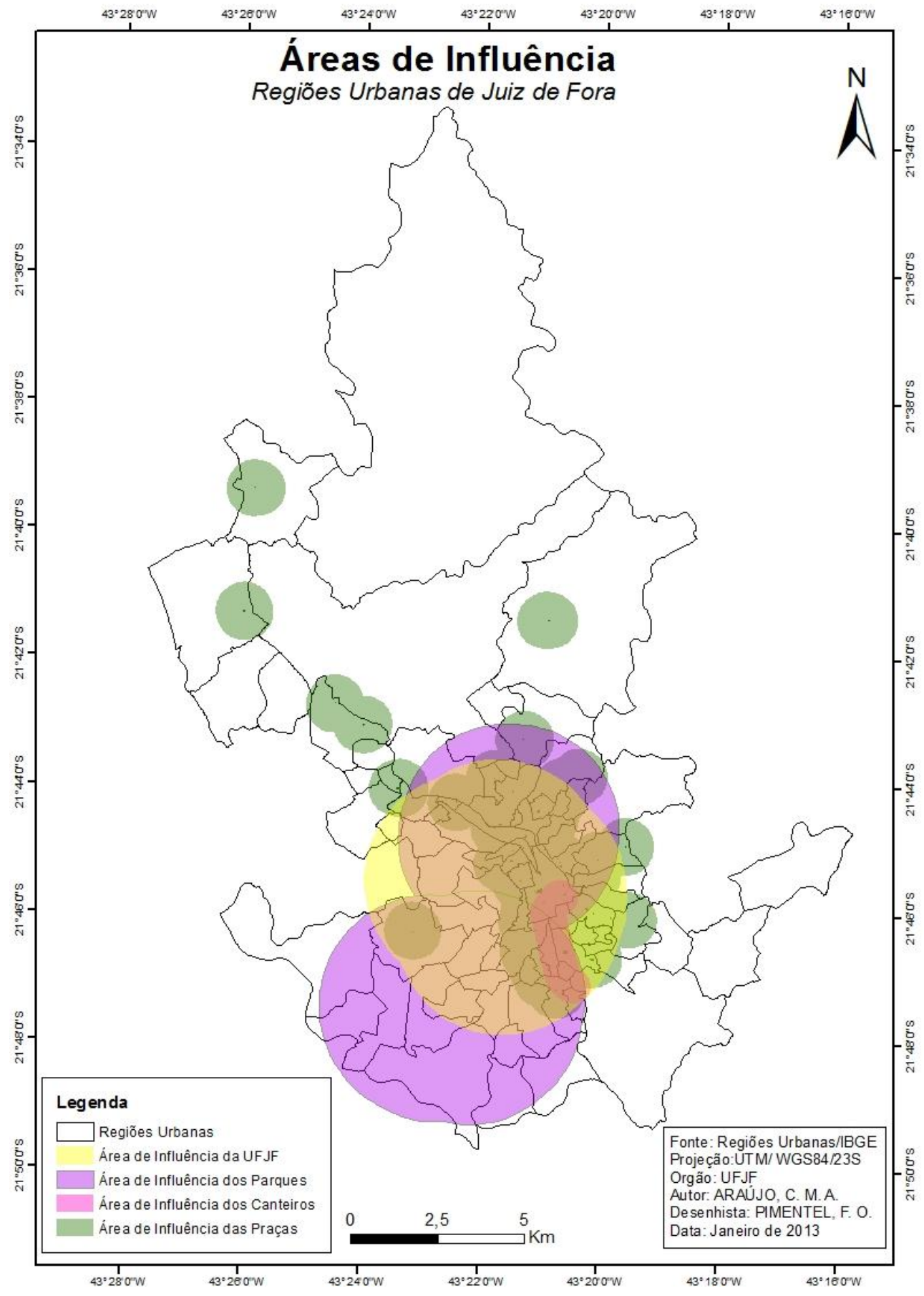

Geo UERJ. Rio de Janeiro - Ano 16, no ${ }^{\circ}$ 25, v.2, $2^{\circ}$ semestre de 2014, pp.250-275

ISSN: 1415-7543 E-ISSN: 1981-9021

http://www.e-publicacoes.uerj.br/index.php/geouerj 
Mapa 4 - Área de influência de parques, praças e canteiros nas RUs de Juiz de Fora

Embora seja um índice pouco utilizado nos trabalhos que versam sobre áreas verdes públicas no Brasil, o PAV é útil porque, quando os dados são transpostos para um mapa, nos auxilia a visualizar onde predominam as áreas verdes e onde elas são deficitárias.

Os valores do PAV foram calculados para as RUs, considerando somente parques, praças e canteiros. Áreas verdes particulares, Reservas Biológicas e outras áreas verdes, quando existentes, não foram considerados. Os valores de PAV para as RUs de Juiz de Fora variaram entre 0 e 34,3\%, sendo que 54 RUs, ou seja 2/3 das RUs, contam com PAV entre 0 e $0,10 \%$ apenas, conforme informa o mapa 5. São elas: Bandeirantes, Barreira, Benfica, Bom Clima, Bomfim, Borboleta, Botanágua, Carlos Chagas, Centenário, Cerâmica, Cesário Alvim, Costa Carvalho, Cruz de Santo Antônio, Cruzeiro do Sul, Esplanada, Floresta, Francisco Bernardino, Fábrica, Grajaú, Grama, Graminha, Granjas Betânia, Ipiranga, Jóquei Clube, Jardim Natal, Linhares, Manoel Honório, Monte Castelo, Nossa Senhora de Lourdes, Nova Califórnia, Nova Era, Novo Horizonte, Progresso, Remonta, Represa, Retiro, São Bernardo, São Geraldo, São Pedro, Sagrado Coração, Salvaterra, Santa Cecília, Santa Cruz, Santa Efigênia, Santa Rita de Cássia, Santo Antônio do Paraibuna, Vale do Ipê, Vila Furtado de Menezes, Vila Ideal, Vila Olavo Costa e Vila Ozanan. Apenas 8 RUs apresentam PAV entre 1,1 e 2,8\%. São elas: Bairu, Boa Vista, Bom Pastor, Centro, Industrial, Jardim Glória, Jardim Santa Helena e São Dimas.

As demais RUs, que são Aeroporto, Alto dos Passos, Barbosa Lage, Cascatinha, Dom Bosco, Eldorado, Granbery, Jardim Paineiras, Morro da Glória, Nossa Senhora Aparecida, Nossa Senhora de Fátima, Poço Rico, São Benedito, São Mateus, Santa Catarina, Santa Luzia, Santa Terezinha, Teixeiras e Vitorino Braga apresentam valores variando até, no máximo, 1\%. O PAV médio das RUs de Juiz de Fora não chega a 5\%, patamar próximo ao encontrado por Henke-Oliveira (1996) para a cidade de São Carlos, SP, de $2,46 \%$. 


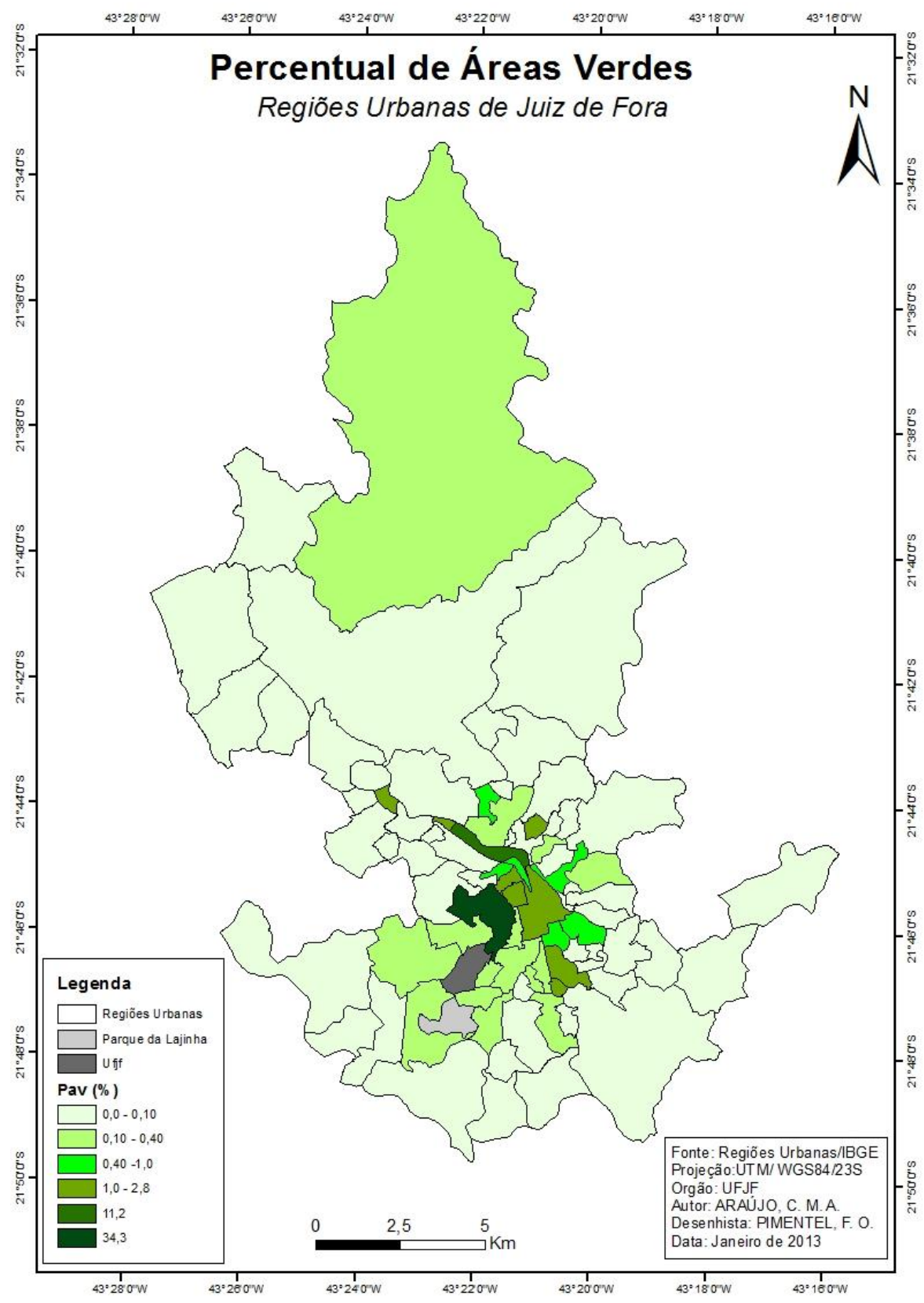

Mapa 5 - Percentual de áreas verdes por RU em Juiz de Fora

\section{Considerações finais}

Sem ter a pretensão de esgotar um assunto tão relevante, e cientes da necessidade de que novas pesquisas lancem luz sobre a temática em foco, chegamos a resultados que revelam uma dinâmica de distribuição e, portanto, de apropriação desigual das áreas verdes públicas nas 81 RUs do município. No que tange aos parques, além do seu reduzido número, apenas três para atender os 511.993 habitantes (IBGE, 
2010), é possível observar que as áreas de influência dos mesmos se sobrepõe, desguarnecendo algumas RUs ao mesmo tempo em que contemplam tantas outras. Os parques influenciam, total ou parcialmente, 68 RUs, ficando 13 sem serem abrangidas. Se, por um lado, a maioria das RUs é influenciada pelos parques, por outro, é importante considerar que a localização dos mesmos ou está em uma RU específica, caso do Parque do Museu Mariano Procópio, ou não está localizado no interior das RUs, fato que obriga o usuário, no mínimo, a ter que se deslocar para acessar essas áreas verdes públicas. Consideramos a necessidade tanto da criação de mais parques que contemplem todas as RUs, quanto a existência de uma logística que proporcione acessibilidade, segurança e manutenção dos mesmos.

Quanto às praças, embora sua distribuição seja mais equitativa que a dos parques, elas são menores e, assim, tem menor raio de influência. 14 RUs não são influenciadas pelas praças, que são por excelência um dos espaços públicos mais procurados pela população. A melhor distribuição das praças em relação aos parques deve ser relativizada, também, pela ocorrência de um maior número delas nas RUs adjacentes à região central da cidade. Para nós, políticas públicas que visem o bem estar da população devem levar em consideração a presença das praças como áreas verdes importantes tanto do ponto de vista ambiental, quanto do social, no sentido de proporcionar aos usuários a oportunidade da realização de atividades ao ar livre ou a simples contemplação e descanso, com conforto e segurança. Preconizamos, desse modo, a necessidade de se repensar a cidade no que tange à presença de espaços livres dedicados ao uso público. A inserção na legislação, como no PDDU, de planejamento que vise à construção de praças, faz-se indispensável não só para aumentar o IAV e aproximar Juiz de Fora das recomendações mínimas da SBAU e outras instituições especializadas, mas também para fomentar a identificação das pessoas com suas RUs, com benefícios para todo o município, se considerarmos, por exemplo, os deslocamentos em veículos automotores em busca das áreas verdes públicas. Isso sem falar na saudável prática de esportes, sobretudo entre as crianças e os jovens.

Os canteiros representam uma situação particular enquanto áreas verdes públicas. Sua função está muito mais relacionada aos benefícios ambientais que ao uso público, uma vez que não oferecem oportunidade de utilização nos moldes dos parques e praças. Em Juiz de Fora, os canteiros se circunscrevem à região central do município. 
Em campo, observou-se que a maioria dos canteiros foi impermeabilizada, talvez para funcionarem como passagem de pedestres. Além do mais, a arborização se apresenta escassa, dado que reflete no baixo IAV apresentado pela maioria das RUs.

Mais uma vez, consideramos a necessidade da construção de ambientes que proporcionem à população condições de aproveitar a cidade ao ar livre. A legislação está pronta, embora sempre passível de melhoras, então, o que falta é colocá-la em prática, o que será conquistado com a participação da sociedade civil, bem informada e ativa na cobrança de ações por parte da municipalidade ou do poder público em outras esferas. Essa pesquisa visa contribuir nesse sentido.

A UFJF constitui uma verdadeira válvula de escape. Apesar de não ser uma área verde pública strictu sensu, a UFJF figura nessa pesquisa como uma, em função de seus atributos e de sua utilização permanente por parcela do povo juizforano. Tudo isso além de exercer grande influência no entorno. Nada menos que 45 RUs são influenciadas total ou parcialmente pela UFJF. É importante a consideração, embora redundante, que o espaço da UFJF é federal, cabendo à municipalidade a criação de áreas verdes públicas que contemplem as RUs como um todo.

Os resultados da pesquisa revelam que Juiz de Fora carece de áreas verdes públicas, que estas são mal distribuídas, influenciam diferentes quantidades de RUs e apresentam problemas de manutenção e acessibilidade. É notável que dentre 81 RUs apenas duas apresentam IAV maior que $15 \mathrm{~m}^{2} / \mathrm{hab}$. Se pretendemos lograr a condição de um município no qual a qualidade ambiental e de vida caminham juntas, é preciso reconsiderar as políticas inerentes às áreas verdes públicas, estas, verdadeiros espaços de socialização e recreação, tão necessários em um mundo em que os valores ligados ao consumismo, ao individualismo e ao produtivismo parece ter ofuscado os espaços livres como locus de convivência e harmonia, em meio ao caos da cidade.

\section{Bibliografia}

ARFELLI, A. C. Áreas verdes e de lazer: considerações para sua compreensão e definição na atividade urbanística de parcelamento do solo. Revista Justitia, São Paulo, , n.33, jan-mar 2004. Disponível em: <http://www.revistajustitia.com.br/artigos/3d0b6b.pdf> Acesso em 26 fev. 2014. 
CAPORUSSO, D.; MATIAS, L. F. Áreas verdes urbanas: avaliação e proposta conceitual. $1^{\circ}$ Simpósio de Pós-Graduação em Geografia do Estado de São Paulo; VII Seminário de Pós-Graduação em Geografia da UNESP. Rio Claro, SP: 2008, p. 71-87.

CAVAlHEIRO, F. et al. Proposição de Terminologia para o Verde Urbano. Boletim Informativo da Sociedade Brasileira de arborização urbana. Rio de Janeiro, v.2, n.3, jul./ago./set., p. 1. 1999.

CAVALHEIRO, F.; DEL PICCHA, P. C. D. Áreas verdes: conceitos, objetivos e diretrizes para o planejamento. In: CONGRESSO BRASILEIRO SOBRE ARBORIZAÇÃO URBANA E ENCONTRO NACIONAL SOBRE ARBORIZAÇÃO URBANA. 1 e 4., 1992, Vitória, Comunicações... Vitória: SBAU, 1992, p. 29-38.

COSTA, R. G. da e FERREIRA, C. C. M. Análise do índice de áreas verdes (IAV) na área central da cidade de Juiz de Fora. Revista Brasileira de Arborização Urbana, Piracicaba, v.4, n.1, p. 39-57. 2009.

Avaliação do Índice de Áreas Verdes (IAV) em 26 Regiões Urbanas na Região Central da Cidade de Juiz de Fora, MG. In: SIMPÓSIO BRASILEIRO DE GEOGRAFIA FÍSICA APLICADA. XII., 2007, Natal. Comunicações... Natal: UFRN, 2007. p. CD.

GUZZO, P. Áreas verdes urbanas. Disponível em: <http //educar.sc.usp.br/biologia/prociencias/areasverdes.html>. 2002. Acesso em 08/11/2013.

HARDER, I. C. F.; RIBEIRO, R. C. S.; TAVARES, A. R. índices de área verde e cobertura vegetal para as praças do município de Vinhedo, SP.Viçosa - MG: Revista Árvore, v. 30, n 2, p. 277-282, 2006.

HENKE-OLIVEIRA. Planejamento ambiental na Cidade de São Carlos (SP) com ênfase nas áreas públicas e áreas verdes: diagnóstico e propostas. 1996. 196f. Dissertação (Mestrado em Ecologia e Recursos Naturais) - Centro de Ciências Biológicas e da saúde, Universidade Federal de São Carlos, 1996.

IBGE, Censo 2010. Disponível em: < http://www.censo2010.ibge.gov.br/amostra/> Acesso em: 26 fev. 2014.

LEFEBVRE, H. A revolução urbana. Belo Horizonte: Editora da UFMG, 2002.

LIMA, A. M. L. P et al. Problemas na utilização na conceituação de termos como espaços livres, áreas verdes e correlatos. Anais do II Congresso Brasileiro de Arborização Urbana. São Luís/MA, 18 a 24 de setembro de 1994, pp. 539-553.

MORAES, A. C. R.; COSTA, W. M. Geografia Crítica: a valorização do espaço. São Paulo: Hucitec, 1999. 
NUCCI, J. C. Qualidade Ambiental e Adensamento Urbano: um estudo de ecologia e planejamento da paisagem aplicado ao distrito de Santa Cecília (MSP). Curitiba: edição do autor, 2008. Disponível em: http://www.geografia.ufpr.br/laboratorios/labs/arquivos/qldade_amb_aden_urbano.pdf Acesso em 12/11/2013.

OLIVEIRA, C. A.; JESUS, I. S. Espacialização e quantificação das áreas verdes no perímetro urbano do município de Rio Branco - Acre. Anais XV Simpósio Brasileiro de Sensoriamento Remoto - SBSR, Curitiba, PR, Brasil, 30 de abril a 05 de maio de 2011, INPE p.0877.

PREFEITURA DE JUIZ DE FORA. Plano Diretor de Desenvolvimento Urbano. Juiz de Fora: PJF, 2004.

REZENDE, R. F. Áreas Verdes Públicas Urbanas em Juiz de Fora -MG: uma avaliação das ações de planejamento urbano. 2010. 273f. Dissertação (Mestrado em Arquitetura e Urbanismo) - Arquitetura e Urbanismo, Universidade Federal Fluminense, 2010.

ROSSET, F. Procedimentos metodológicos para estimativa do Índice de Áreas Verdes Públicas. Estudo de caso: Erechim: RS. 2005. 78f. Dissertação (Mestrado em Ecologia e Recursos Naturais) - Centro de Ciências Biológicas e da saúde, Universidade Federal de São Carlos, 2005.

WILlians, R. Constructing the Public Good: Social Movements and Cultural Resources. Social Problems: Vol. 42, No. 1, 1995, pp. 124-144.

ZANIN, E. M. Caracterização ambiental da paisagem urbana de Erechim e do Parque Municipal Longines Malinowski - Erechim - RS. 2002. 176f. Tese (Doutorado em Ecologia e Recursos Naturais) - Centro de Ciências Biológicas e da saúde, Universidade Federal de São Carlos, 2002.

Artigo recebido para publicação em abril de 2014.

Artigo aceito para publicação em novembro de 2014. 